\section{Levels of attitudes toward environment and environmental awareness of students in international baccalaureate diploma program and students in national program}

\section{Ümit Yaşatürk Midilli ${ }^{1}$ Tahir Atıci ${ }^{2}$}

\author{
Uluslararası bakalorya \\ diploma programı ve ulusal \\ programda öğrenim gören \\ öğrencilerin çevreye yönelik \\ tutum ve çevre farkındalık \\ düzeyleri
}

\begin{abstract}
This research will be covering the comparison of TED Ankara College IB and national program students' attitudes toward environment, and their their levels of awarness in terms of this subject. The research also covers the variable of gender in comparison of levels of awarness and attitude toward environment between the students who are taking the IBDP "ESS" course and who aren't. The statistics in the research is obtained by "Attitude toward environment scale" and "Environmental awarness scale". The scales and the research had been done on 25 students from IBDP TurkishMathematics track, 45 students from IBDP Math-Science track and 39 students from the national program. The 109 students who had taken part in the research consists of 57 female and 52 male students. The findings of the survey show that there is a significant relation between students' attitudes toward environment and environmental awareness levels and gender, but there is not a significant difference of students' attitudes environment

and
\end{abstract}

Özet

Bu araştırma, TED Ankara Koleji Vakfı Özel Lisesi'nde uygulanan Uluslararası Bakalorya Diploma Programı ve ulusal programda öğrenim gören öğrencilerin çevreye yönelik tutum ve çevre farkındalık düzeylerinin karşılaştırılmasını amaçlamaktadır. Araştırmada ayrıca cinsiyet değişkenine göre ve UBDP'de "Çevre Sistemleri" dersi alan ve almayan öğrencilerin de çevreye yönelik tutum ve çevre farkındalık düzeylerinin karşılaştırılması amaçlanmıştır. Araştırmada sunulan veriler, "Çevre Tutum Ölçeği”" ve "Çevre Farkındalık Ölçeği”"nden elde edilmiştir. Ölçekler, TED Ankara Koleji’nde öğrenim gören UBDP Matematik- Fen alanındaki 45 öğrenciye, UBDP Türkçe-Matematik alanındaki 25 öğrenciye ve ulusal programdaki 39 öğrenciye uygulanmıştır. Araştırmaya katılan 109 öğrencinin 57'si k1z, 52'si erkektir. Araştırmanın bulguları, öğrencilerin çevreye yönelik tutum ve farkındalık düzeyleri ile cinsiyetleri arasında anlamlı bir ilişki olduğunu, fakat öğrencilerin çevreye yönelik tutum ve

\footnotetext{
${ }^{1}$ Ph.D. Student, Gazi University, Gazi Education Faculty, umityasaturk@hotmail.com

2 Prof. Dr., Gazi University, Gazi Education Faculty, tatici@gmail.com
} 
Midilli, Ü., \& Atıı, T. (2019). Uluslararası bakalorya diploma programı ve ulusal programda öğrenim gören öğrencilerin çevreye yönelik tutum ve çevre farkındalık düzeyleri. Journal of Human Sciences, 16(3), 846-856. doi: $10.14687 /$ ihs.v16i3.5530

environmental awareness levels when the track and program variables are taken into consideration. Results also show that there is a linear correlation between the attitude toward environment and environmental awareness levels of both students in IBDP taking the "Environmental Systems and Societies" course and the students taking the national program curriculum. Findings put forth in the study are important for mirroring the levels of attitudes toward environment and environmental awareness levels of students who are taking an intensive environmental education in an international programme and of students who are taking environmental education in biology curriculum of the national programme. In the light of the findings of the investigation, importance of expert advice in the process of preparing curriculum about the environmental education and encouraging students to actively participate in the activities about environment is highlighted.

Keywords: Attitude toward environment; environmental awareness; environmental education; environmental systems and societies; international baccalaureate diploma programme.

\section{(Extended English summary is at the end of} this document) farkındalık düzeylerinde alan ve program değişkeni göz önünde tutulduğunda anlamlı bir farklılık olmadığını ortaya koymuştur. Bulgular ayrica UBDP'ında "Çevre Sistemleri" dersi alan ve ulusal program öğrencilerinin çevreye yönelik tutum ve çevre farkındalık düzeyleri arasında anlamlı lineer bir ilişki olduğunu göstermiştir. Çalışmada ortaya konulan bulgular, uluslararası bir programda yoğun bir şekilde çevre eğitimi ile ilgili ders alan ögrrencilerle ulusal biyoloji öğretim programı dahilinde çevre eğitimi gören öğrencilerin çevreye yönelik tutumları ve çevre farkındalık düzeylerini yansıtması açısından önem taşımaktadır. Araştırmanın bulguları 1şığında çevre eğitimi programları hazırlanırken uzman görüşlerine başvurulmasının ve çevre ile ilgili aktivitelere öğrencilerin aktif katılımlarının önemine dikkat çekilmektedir.

Anahtar Kelimeler: Çevreye yönelik tutum; çevre farkındalık; çevre eğitimi; çevre sistemleri dersi; uluslararası bakalorya diploma programı

\section{Giriş}

Çevre bilincinin ve duyarlılığının geliştirilmesi, yaşanılabilir bir çevrenin sürekliliğini sağlama açısından gereklidir. Bu da ancak gerekli ve yeterli özelliklere sahip bireyleri yetiştirmeye dönük çevre eğitimi ile mümkün olacaktır.

Çevre sorunlarının engellenmesi ve çevrenin korunması için en önemli unsurlardan biri çevre ve çevre sorunlarına duyarlı, çevreyi oluşturan elemanların ve işleyişlerinin farkında olan, bilinçli bireyler yetiştirmek ve onlara çevre konusunda olumlu tutumlar kazandırabilmektir. Çevreyi korumak için yasalar koymak veya çevre sorunlarının üstesinden gelecek teknolojiyi üretmek değil birincil olarak çevre üzerinde en fazla etkiye sahip olan insanın eğitilmesi gerekmektedir. Çevreye karşı olumsuz tutuma sahip bireylerin çevre sorunlarına duyarsız olacağı ve hatta çevreye sorun yaratmaya devam edeceği düşünülebilir.

Çocuklarımızda çevreyi korumalarına yardım edecek zengin bir çevresel duygu ve düşünce tesis edebilirsek, çevreyi korumaya yönelik kanunlar yapmaktan daha etkili bir şey yapmış olacağız (Öztürk ve Diğerleri, 1998:99). Çünkü Ramsey ve Rickson, (1976)'a göre doğayı etkileyen en önemli etken devletlerin çevre politikaları değil, insanların çevre konularında rol alma istekleri ve çevreye verecekleri zararları en aza indirme çabalarıdır (Akt. Aydın, Doğan ve Başlar, 2007:13). 
Midilli, Ü., \& Atıı, T. (2019). Uluslararası bakalorya diploma programı ve ulusal programda öğrenim gören öğrencilerin çevreye yönelik tutum ve çevre farkındalık düzeyleri. Journal of Human Sciences, 16(3), 846-856. doi: $10.14687 /$ ihs.v16i3.5530

Çevre eğitimi, tüm dünyanın gündeminde olan çevre sorunlanının ortaya çıkardığı bireysel ve toplumsal bir ihtiyaç haline gelmiştir. Çevre eğitiminin amac1 toplumun tüm kesimlerini çevre konusunda bilinçlendirmek, bilgilendirmek, olumlu ve kalıcı davranış değişikliklerini kazandırmak ve bireylerin aktif katılımlarını sağlamaktır. Bu nedenle, çevre ile ilgili konularda aktif katılım sağlayacak, olumsuzluklara karşı tepki oluşturacak, bireysel çıkarların toplumsal çıkarlardan ayrı düşünülemeyeceği gerçeğini kavratacak bir eğitim yöntemi ve halkın katılımını amaçlayan eğitim sistemi, kitlelerin düşünme ve karar verme gücünü de geliştirecektir. Çevre eğitimi, yalnız bilgi vermek ve sorumluluk hissi oluşturmakla kalmamalı, insan davranışına da etki yapmalıdır (Çevre ve Orman Bakanlı̆̆1, 1996:455).

1977'de UNESCO ve UNEP'in işbirliği ile Tiflis'te toplanan Hükümetler arası Çevre Eğitimi Konferansı'nda Çevre Eğitiminin hedef, amaç ve esasları belirlenmiştir. Tiflis Bildirgesi'ne göre bir çevre eğitiminden beklenen amaç; bireylere çevre sorunlarına yönelik bilinç, bilgi, tutum ve beceri kazandırmak ve bu sorunların çözümüne yönelik katılımlarını sağlamaktır (Ünal ve Dımışkı, 1999:143). Görüldüğü üzere, çevre eğitiminin amacı yaratıc1, sorumluluk sahibi ve katılımcı çevre bilincine sahip bireyler yetiştirmektir. Bireylerin çevreyle ilgili değer, tutum ve davranışlarında meydana gelecek olumlu değişiklikler yaşanılabilir bir çevrenin oluşmasına ve bunun sürdürülmesine katk1 sağlayacaktır.

Öğrencilere çevreye yönelik değer sistemi kazandırmayı amaçlayan bir çevre eğitimi için, tüm öğrencilerin üniversiteye devam edemeyeceği ve üniversitelerin çevreyle ilgili bölümleri dışındaki bölümlerde çevre konusuyla ilgili davranış değişikliği amacı merkeze alınamadığ1 göz önünde bulundurulduğunda, orta öğretim seviyesi önemli bir yere sahip olmaktadır.

Hem ortaöğretim düzeyindeki hem de üniversitelerin ilgili bölümlerindeki öğrencilerin çevreye yönelik tutum, davranış ve farkındalık düzeyini ele alan birçok araştırma yapılmıştır.

Pooley ve O’Connor (2000) çevreye yönelik tutumun temelini araştırmış, çevreye yönelik tutumun insanların çevre hakkında ne hissettiği ve inandığına bağlı olarak şekillendiğini, çevre eğitim programları düzenlenirken bilginin aksine çevre tutum, duygu ve düşünceleri değiştirebilen çevre eğitimcilerin bilgi kaynağı olarak alınması gerekliliği üzerinde durmuştur.

Oğuz\& Çakcı\& Kavas (2011) tarafindan yapılan, Peyzaj mimarlı̆̆ı, çevre mühendisliği ve şehir ve bölge planlama bölümü öğrencilerinin çevre ile ilgili konularda farkındalık, bilinç ve duyarllık seviyelerinin belirlenmesinin amaçlandığ bir araştırmada; çevre ile ilgili konularda farkındalık ve duyarlılık seviyesi öğrencilerin okudukları sinıflardan bağımsız olduğu, çevresel sorunlar ve kaynakların korunması konusunda kavramsal olarak bilgi sahibi olsalar da gündelik yaşamlarında tutum ve davranış biçimleri aynı seviyede olmadığı, çevre ile ilgili verilen derslerin tutum ve davranışları yönlendirmedeki etkinliğinin sorgulanması gerekliliği, yükseköğretim kurumlarında çevre eğitimi konusunda ulusal strateji ve politikalara ihtiyaç duyulduğu ortaya konulmuştur.

Kılınç (2010), projeye dayalı öğrenme ortamlarının çevre dostu davranışların oluşturulmasındaki etkililiğini araştırmış ve projeye dayalı öğrenme ortamının öğrencilerin çevre koruma ile ilgili davranışlarında olumlu değişimlere neden olduğunu gözlemiştir.

Hanna (1995)'nın araştırmasında bilgi edinimi açısından, çevre programına katılanlar daha başarll bulunurken; tutum açısından, birbirine yaklaşı artı̧lar belirlemiştir. Palmberg ve Kuru (2000), öğrencilerin çevresel bilgi ve farkındalıklarında artış ve doğaya yönelik daha empatik yaklaşımlarının olduğunu fakat çevresel bakış açılarının çoğunlukla 'egosentrik' olduğunu belirtmektedir. Özdemir (2010) öğrencilerin, çevresel algı düzeyleri ve farkındalıkları arttıkça, çevresel konularda daha çok endişe taşıdıklarını; buna bağlı olarak da çevresel konularda daha sorumlu davranış sergilediklerini ifade etmektedir.

Xingcune (2004)'a göre çevre bilgisi çok geniş bir bilim alanına (jeoloji, kimya, fizik, matematik vb.) kapsamasına rağmen özellikle ekoloji tabanlı iyi bir biyoloji eğitimi, çevre eğitiminin temelidir. Özellikle ekoloji, genetik ve evrim gibi temel biyoloji bilgilerine sahip olmadan doğa kanunlarını anlamak, çevresel dengeyi sürdürmek ve biyo-çeşitliliği korumak mümkün değildir. Türkiye' de de çevre ile ilgili bilgiler okul çağındaki öğrencilere genellikle ilköğretim de Fen ve Teknoloji, 
Midilli, Ü., \& Atıı, T. (2019). Uluslararası bakalorya diploma programı ve ulusal programda öğrenim gören öğrencilerin çevreye yönelik tutum ve çevre farkındalık düzeyleri. Journal of Human Sciences, 16(3), 846-856. doi: $10.14687 /$ ihs.v16i3.5530

ortaöğretimde ise Biyoloji derslerinde verilmekte, çevre ile ilgili dersler ise zorunlu dersler arasında yer almayıp seçmeli ders olarak öğrenci tercihine bırakılmaktadır (Xingcune, 2004).

MEB Biyoloji dersi öğretim programı göz önüne alındığında; 9. sınıfta Güncel Çevre Sorunları ve İnsan, Doğal Kaynaklar ve Biyolojik Çeşitliliğin Korunması başlıklarını içeren bir ünite, 10. sınıfta Ekosistem Ekolojisi ve Biyomlar ünitesi ve 12. sinıfta Kommünite ve Populasyon Ekolojisi başlıklarıyla çevre eğitimi Biyoloji dersi öğretim programı kapsamında bulunmaktadır (bttp:// mebk12.meb.gov.tr/meb_iys_dosyalar/31/01/972850/dosyalar/2013_07/05032334_biyoloji_912.p $d f)$.

Uluslararası Bakalorya Diploma Programı (UBDP), merkezi Cenevre'de bulunan Uluslararası Bakalorya organizasyonu (IBO) tarafindan uygulanan ve 16-19 yaş arası öğrenciler için hazırlanmış, geniş kapsaml, üniversite öncesi iki yıllık bir programdır. Ülkemizde Milli Eğitim Bakanlığı tarafından verilen diplomanın yanı sıra öğrencilere uluslararası geçerliliği olan bir diploma sağlar (ibo.org).

UBDP, uygulandığı ülkelerin kendi eğitim gereksinimlerine göre değişikliklere olanak tanıyan, uyarlanabilen bir programdır. UBDP eğitimi, öğrencileri merkeze alır, öğretme ve öğrenmeye etkili yaklaşımlar geliştirir, küresel bağlamda çalışır ve anlamlı içeriğin keşfedilmesine 1şık tutar. Ayrıca araştırma, eylem ve sorgulama yoluyla küresel zorluklarla ilişkili bir öğrenci toplumu oluşturmayı amaçlar. UBDP öğretim programı, DP çekirdeği ve 6 konu grubundan oluşmaktadır. 3 zorunlu bileşenden (bilgi kuramı, uzun süreli tez ve yaratıcılık- eylem- hizmet) oluşan DP çekirdeği öğrencilerin eğitim tecrübelerini geliştirmeyi ve onların bilgi ve becerilerini uygulamaya dökmelerini sağlamayı amaçlar. Diğer 6 konu grubu ise dil ve edebiyat çalışmaları, dil edinme, birey ve toplumlar, fen bilimleri, matematik ve sanattan oluşmaktadır (ibo.org). Biyoloji dersi bu konu gruplarından fen bilimleri grubunda bulunmaktadır. Öğrenciler Biyoloji dersini ileri veya standart düzey olarak alabilmektedirler. UBDP Biyoloji dersi öğretim programı, çekirdek (core), ek ileri düzey ve seçmeli konu başlıklarından oluşmaktadır. Standart düzey öğrencileri ek ileri düzey konu başlıklarını almamaktadır. Her öğrenci UBDP dış değerlendirme olarak adlandırılan sınavlarda seçmeli konulardan sadece birinden sorumlu tutulurlar ve bunun seçimi öğrenciye bırakılmıştır. UBDP Biyoloji dersi öğretim programında çevre eğitimi kapsamındaki başlıklar çekirdek konularında Ekoloji (Ecology) ve seçmeli konu başlıklarında Ekoloji ve Koruma (Ecology and Conservation) başlıkları altında bulunmaktadır (ibo.org).

Birey ve toplumlar grubunda bulunan ve Türkçe'ye Çevre Sistemleri olarak çevrilmiş olan Environmental Systems and Society dersi öğretim programı iki ylllk süreyle UBDP kapsamında okutulur ve aşağıdaki başlıkları içerir:

- Çevre sistemleri ve toplum kuruluşları

- Ekosistemler ve ekoloji

- Biyolojik çeşitlilik ve korunması

- Su ve sucul besin üretim sistemleri ve toplumlar

- Atmosferik sistemler ve toplumlar

- İklim değişikliği ve enerji üretimi

- İnsan sistemleri ve kaynak kullanımı (ibo.org).

Öğretim programı incelendiğinde bu dersin, çevreyi oluşturan tüm ögeleri tüme varım yoluyla ele alarak her bir ögeyi kendi içinde incelediği ve sonuçta bütün için ifade ettiği anlamı ortaya koyduğu görülür. Bu bağlamda bu dersin amacının;

- Çevre değer sistemi kazandırmak (Environmental Value Systems)

- Çevre kirliliği nedenleri ve sonuçları hakkında bilinç kazandırmak

- Çevreyi oluşturan öğelerin önemini ve bunların korunması için alınması gereken tedbirlerle ilgili bilinç kazandırmak

- Kaynakların sürdürülebilir kullanımıyla çevreye karşı duyarlı bir yaşam modeli kazandırmak 
Midilli, Ü., \& Atıı, T. (2019). Uluslararası bakalorya diploma programı ve ulusal programda öğrenim gören öğrencilerin çevreye yönelik tutum ve çevre farkındalık düzeyleri. Journal of Human Sciences, 16(3), 846-856. doi: $10.14687 /$ ihs.v16i3.5530

- Ortak kaynakların kullanımında toplumsal hareket bilincini kazandırmak (Tragedy of The Common)

- Çevre üzerindeki insan etkisinin en aza indirilmesinin önemini kavratmak olduğu anlaşılır.

\section{Araştırmanın Amacı:}

Araştırma, TED Ankara Koleji Vakfi Özel Lisesi'nde uygulanan UBDP ve ulusal programda öğrenim gören öğrencilerin çevreye yönelik tutum ve çevre farkındalık düzeylerinin karşılaştırılmasını amaçlamaktadır. Araştırmada ayrıca cinsiyet değişkenine göre ve UBDP'de "Çevre Sistemleri”" dersi alan ve almayan öğrencilerin de çevreye yönelik tutum ve çevre farkındalık düzeylerinin karşılaşturılması amaçlanmıştır.

\section{Yöntem}

\subsection{Araştırma Modeli/Deseni}

Çalişmada, araştırma yöntemlerinden tanıtıcı araştırma yöntemi kullanılmıştır. Bu yöntem, belirli bir bilgi kümesinin ilgi duyulan bazı özelliklerini ortaya koymayı amaçlayan araştırma türüdür. Tanıtıcı araşturmaların amacı genelde neden sonuç ilişkilerini gözlemlemek değil durum ya da olayların genel niteliklerini belirleyebilmektir (Büyüköztürk, 2003).

\section{2. Çalışma Grubu}

Araştırmanın amacına göre deneklerin seçiminde koşullu örnekleme yapılmışır. Bu tür örneklemelerde denek kitlesi büyük tutulduğunda bile deneklerde aranan özellikler önceden belirlenir ve buna uygun denekler seçilir (Büyüköztürk, 2003).

Teorik olarak çalışmanın evrenini hem ulusal program hem de UBDP uygulayan okullardaki öğrencilerden Çevre Sistemleri ve Biyoloji dersi alan öğrenciler oluşturmaktadır. Her iki programı da uygulayan okullardaki öğrenci sayıları göz önünde tutulduğunda çalışlabilir evrenin bir bölümü ve büyük bir bölümü olarak belirtilen kriterlerdeki okullar içinde en yüksek öğrenci mevcuduna sahip olan TED Ankara Koleji Vakfi Özel Lisesi alınmıştır.TED Ankara Koleji Vakfi Özel Lisesi'nde, 1999-2000 öğretim yılından itibaren UBDP uygulanmaya başlamış ve 2011-2012 öğretim yllında da Çevre Sistemleri dersi UBDP kapsamına alınmıştır. Hem MEB lise diploması hem de UBDP diploması veren bir okul olması itibariyle araştırmanın örneklemini bu okulda okuyan UBDP ve MEB ulusal müfredatına tabi olan öğrenciler oluşturmaktadır. Okuldaki UBDP matematik- fen alanında öğrenim gören öğrenciler MEB öğretim programı dâhilindeki Biyoloji ve Çevre Sistemleri derslerini alırken UBDP Türkçe- Matematik alanındaki öğrenciler sadece UBDP Biyoloji dersini, MEB ulusal programdaki öğrenciler ise sadece MEB öğretim programı dâhilindeki Biyoloji dersini almaktadırlar. Bu yüzden araştırmada ölçekler, TED Ankara Koleji’nde öğrenim gören UBDP Matematik- Fen alanındaki 45 öğrenciye, UBDP Türkçe-Matematik alanındaki 25 öğrenciye ve ulusal programdaki 39 öğrenciye uygulanmıştır. Araştırmaya katılan 109 öğrencinin 57'si kız, 52'si erkektir.

\subsection{Veri Toplama Araçları ve Verilerin Çözümlenmesi}

Araştırmanın amacı doğrultusunda öğrencilerin çevreye yönelik tutumlarının belirlenmesi için Berberoğlu ve Uygun (2012) tarafindan geliştirilen "Çevre Tutum Ölçeği” ve "Çevre Farkındalık Ölçeğı” uygulanmıştır. Ölçeğin güvenirlik katsayısı 0,80 olarak, hesaplanmış ve doğrulayıc1 faktör analizi sonucu uyum iyiliği değerleri kabul edilen standartlarda olduğu belirlenmiştir. Ayrıca çevre farkındalık ölçeğinin güvenirlik katsayısı 0,85 olarak, hesaplanmış ve doğrulayıcı faktör analizi sonucu, uyum iyiliği değerleri kabul edilen standartlarda olduğu belirlenmiştir.

Verilerin analizi; SPSS 22.0 paket programı kullanılarak betimsel istatistik, ilişkisiz örneklemler için t-testi, tek yönlü varyans analizi (ANOVA) ve Pearson korelasyon testi uygulanmıştır. 
Midilli, Ü., \& Atıı, T. (2019). Uluslararası bakalorya diploma programı ve ulusal programda öğrenim gören öğrencilerin çevreye yönelik tutum ve çevre farkındalık düzeyleri. Journal of Human Sciences, 16(3), 846-856. doi: $10.14687 /$ ihs.v16i3.5530

\subsection{Araştırmanın Sınırlilıkları}

Öğrenciler arasındaki akademik başarı farklıllğını göz ardı edebilmek amacıyla araştırmaya tüm programlardaki Çevre Sistemleri ve Biyoloji ders ortalaması 11. sınıf sonunda 70 ve üstü olan öğrenciler dâhil edilmiştir. 70 not ortalaması, araştırmanın yapıldığı dönemde TED Ankara Koleji Vakfi Özel Lisesi’nde UBDP Biyoloji dersini ileri düzey almak için kriter olarak kullanılmıştır. Çevre Sistemleri dersi öğretim programının 6/8'lik kısmı 11. sınıfta tamamlandığ1 ve ulusal program öğrencileri de çevre sorunlarıly ilgili Biyoloji öğretim programı kapsamını 12. sınıftan önce tamamladıkları için araştırma 12. sınıfin birinci dönemindeki öğrencilerle gerçekleştirilmiştir.

\section{Bulgular ve Yorum}

4.1. Öğrencilerinin Çevreye Yönelik Tutum ve Farkındalık Düzeylerinin "Cinsiyete" Göre Karşılaştırılması

Öğrencilerin çevreye yönelik tutum ve farkındalık düzeylerinin "insiyete” göre anlamlı farklılık gösterip göstermediğini belirlemek için "bağımsız örneklemler t-testi” yapılmış ve sonuçlar tablo 1'de gösterilmiştir.

Tablo-1 Cinsiyete Göre Tutum ve Farkındalık Puanlarına İlişkin Bağımsız Örneklem t-Testi Sonuçları

\begin{tabular}{|l|l|l|l|l|l|}
\hline & Cinsiyet & $\mathrm{N}$ & Mean & $\mathrm{t}$ & $\mathrm{p}$ \\
\hline \multirow{2}{*}{ Tutum } & Kiz & 57 & 84.52 & \multirow{2}{*}{5.397} & \multirow{2}{*}{$.000^{*}$} \\
\cline { 2 - 6 } & Erkek & 52 & 74.30 & & \multirow{2}{*}{1.308} \\
\hline \multirow{2}{*}{ Farkındalık } & K1z & 57 & 83.26 & .194 \\
\cline { 2 - 4 } & Erkek & 52 & 81.59 & & \\
\hline
\end{tabular}

Tablo 1 incelendiğinde; kız öğrencilerin çevreye yönelik tutum ve farkındalık düzeylerinin ortalamaları (sırasıyla $\bar{X}=84.52$ ve $\bar{X}=83.26$ ), erkek öğrencilerin çevreye yönelik tutum ve farkındalık düzeylerinin ortalamalarından (sırasıyla $\bar{X}=74.30$ ve $\bar{X}=81.59$ ) yüksek olduğu görülmektedir. Bu farklılı̆̆ı anlamlı olup olmadığı için yapılan t-testi sonuçlarına göre; araştırmaya dâhil edilen öğrencilerin çevreye yönelik tutum ve farkındalık düzeyleri cinsiyete göre .05 düzeyinde anlamlı farklılık göstermiştir. Bu bulgu, öğrencilerin çevreye yönelik tutum ve farkındalık düzeyleri ile cinsiyetleri arasında anlamlı bir ilişki olduğu şeklinde de yorumlanabilir.

4. 2. UBDP ve Ulusal Program öğrencilerinin Çevreye Yönelik Tutum ve Farkındalık Düzeylerinin Karşılaştırılması

Öğrencilerin çevreye yönelik tutum ve farkındalık düzeylerinin "programa" göre anlamlı farkl1lık gösterip göstermediğini belirlemek için “bağımsız örneklemler t-testi” yapılmış ve sonuçlar tablo 2'de gösterilmiştir.

Tablo-2 Programa Göre Tutum ve Farkındalık Puanlarına İlişkin Bağımsız Örneklem t-Testi Sonuçları

\begin{tabular}{|l|l|l|l|l|l|}
\hline & Birleşik & $\mathrm{N}$ & Mean & $\mathrm{t}$ & $\mathrm{p}$ \\
\hline \multirow{2}{*}{ Tutum } & UB & 69 & 79.98 & \multirow{2}{*}{.412} & \multirow{2}{*}{.681} \\
\cline { 2 - 5 } & Ulusal & 40 & 79.07 & & \multirow{2}{*}{.482} \\
\hline \multirow{2}{*}{ Farkindalık } & UB & 69 & 82.08 & .436 \\
\cline { 2 - 4 } & Ulusal & 40 & 83.12 & & \\
\hline
\end{tabular}


Midilli, Ü., \& Atıı, T. (2019). Uluslararası bakalorya diploma programı ve ulusal programda öğrenim gören öğrencilerin çevreye yönelik tutum ve çevre farkındalık düzeyleri. Journal of Human Sciences, 16(3), 846-856. doi: $10.14687 /$ ihs.v16i3.5530

Tablo 2 incelendiğinde; UBDP öğrencilerinin çevreye yönelik tutum ve farkındalık düzeylerinin ortalamalarının sırasıyla $\bar{X}=79.98$ ve $\bar{X}=82.08$, ulusal program öğrencilerinin çevreye yönelik tutum ve farkındalık düzeylerinin ortalamalarının sırasıyla $\bar{X}=79.07$ ve $\bar{X}=83.12$ olduğu görülmektedir. Tutum skorlarına bakıldığında UBDP öğrencilerinin ortalamalarının ulusal program öğrencilerinin ortalamalarından yüksek olduğu, farkındalık skorlarına bakıldığında ise durumun tam tersi olduğu görülmüştür. Bu farklılı̆̆ın anlamlı olup olmadığ1 için yapılan t-testi sonuçlarına göre; araştırmaya dâhil edilen öğrencilerin çevreye yönelik tutum ve farkındalık düzeyleri programa göre 0,05 düzeyinde anlamlı farklılık göstermemiştir.

4.3. UBDP Matematik- Fen ve UBDP Türkçe- Matematik Bölümlerindeki Öğrencilerin Çevreye Yönelik Tutum ve Farkındalık Düzeylerinin Karşılaştırılması

Öğrencilerin çevreye yönelik tutum ve farkındalık düzeylerinin "alana" göre anlamlı farklılık gösterip göstermediğini belirlemek için “bağımsı̨ örneklemler t-testi” yapilmış ve sonuçlar tablo 3’te gösterilmiştir.

Tablo-3 Alana Göre Tutum ve Farkındalık Puanlarına İlişkin Bağımsız Örneklem t-Testi Sonuçları

\begin{tabular}{|l|l|l|l|l|l|}
\hline & & & & \\
\hline \multirow{2}{*}{ Tutum } & Program & $\mathrm{N}$ & Mean & $\mathrm{t}$ & $\mathrm{p}$ \\
\cline { 2 - 4 } & UBMF & 44 & 80.20 & \multirow{2}{*}{.217} & \multirow{2}{*}{.829} \\
\hline \multirow{2}{*}{ Farkindalik } & UBMF & 25 & 79.60 & & \multirow{2}{*}{.579} \\
\cline { 2 - 4 } & UBTM & 25 & 81.44 & & \\
\hline
\end{tabular}

Tablo 3 incelendiğinde; UBDP Matematik -Fen alanındaki öğrencilerin çevreye yönelik tutum ve farkındalık düzeylerinin ortalamalarının sırasıyla $\bar{X}=80.20$ ve $\bar{X}=82.45$, Türkçe- Matematik alanındaki öğrencilerin çevreye yönelik tutum ve farkındalık düzeylerinin ortalamalarının sırasıyla $\bar{X}=79.60$ ve $\bar{X}=81.44$ olduğu görülmektedir. Hem tutum hem de farkındalık skorlarına bakıldığında MF öğrencilerinin ortalamalarının TM öğrencilerinin ortalamalarından yüksek olduğu görülmüsstür. $\mathrm{Bu}$ farklılığın anlamlı olup olmadığ için yapılan t-testi sonuçlarına göre; araştırmaya dâhil edilen öğrencilerin çevreye yönelik tutum ve farkındalık düzeyleri alana göre .05 düzeyinde anlamlı farklılık göstermemiştir.

4.4. Tüm programlardaki öğrencilerin Çevreye Yönelik Tutum ve Çevre Farkındalık Düzeyleri Arasındaki İlişkinin Araştırılması

Öğrencilerin çevreye yönelik tutum ve farkındalık düzeyleri arasında anlamlı bir ilişki olup olmadığını belirlemek için "Pearson Korelasyon testi” yapılmış ve sonuçlar tablo 4'te gösterilmiştir.

Tablo-4 Çevreye Yönelik Tutum ve Farkındalık Düzeyleri Arasındaki İlişki

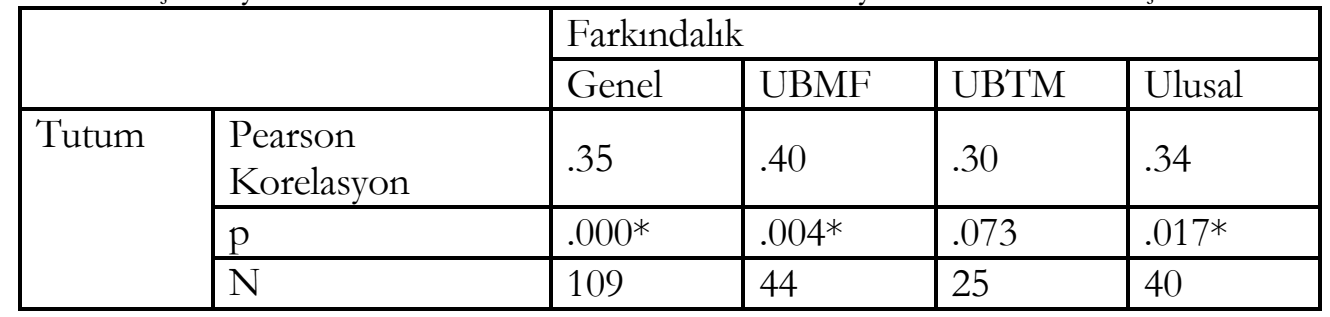

${ }^{*} \mathrm{p}<.05$

Elde edilen verilere göre, UBDP MF ve Ulusal program öğrencilerinin çevreye yönelik tutum ve farkındalık düzeyleri arasında anlamlı doğrusal ve zayıf bir ilişki olduğu $(p<.05)$ saptanmıştır. 
Midilli, Ü., \& Atıı, T. (2019). Uluslararası bakalorya diploma programı ve ulusal programda öğrenim gören öğrencilerin çevreye yönelik tutum ve çevre farkındalık düzeyleri. Journal of Human Sciences, 16(3), 846-856. doi: $10.14687 /$ ihs.v16i3.5530

\section{Tartışma, Sonuç ve Öneriler}

$\mathrm{Bu}$ araştırma, TED Ankara Koleji Vakfi Özel Lisesi’nde farklı programlarda öğrenim gören öğrencilerin çevreye yönelik tutum ve çevre farkındalık düzeylerini belirlemek ve tutum ve farkındalık arasındaki ilişkiyi ortaya koymak amacıyla yapılmıştır. Bu amaçla öğrencilere çevreye yönelik tutum ve çevre farkındalık ölçekleri uygulanmıs, ölçek sonuçları her bir grubu kendi içinde ve birbiriyle karşılaştırarak değerlendirmek için kullanılmıştır.

Araştırmanın sonunda, kız öğrencilerle erkek öğrenciler arasında hem tutum hem farkındalık bakımından anlamlı bir farklılık görülmüştür. Hem tutum hem de farkındalığa ait ölçekten alınan ortalamaların, kız öğrenciler için erkek öğrencilerden yüksek olduğu görülmüştür.

Alan fark1 gözetilmeksizin UBDP öğrencileriyle ulusal program öğrencilerinin çevreye yönelik tutum ve farkındalık düzeylerinin ortalama değerleri arasında anlamlı bir farklılık gözlenmemiştir.

UBDP içindeki Çevre Sistemleri dersi alan MF öğrencileriyle aynı programdaki Çevre Sistemleri dersi almayan fakat ileri düzey Biyoloji dersi alan TM öğrencilerinin çevreye yönelik tutum ve farkındalık düzeylerinin ortalamaları arasında da anlamlı farklılık gözlenmemiştir.

Tüm gruplar göz önüne alındığında, öğrencilerin çevreye yönelik tutum ve farkındalık düzeyleri arasında anlamlı ve zayıf bir ilişki olduğu gözlenmiştir.

Bu sonuçlar 1şı̆̆ında, öğrencilerin dâhil oldukları programlar içinde çevreye yönelik tutum ve farkındalık düzeyinin yüksek olması beklenen grup Çevre Sistemleri dersi alan UBDP-MF öğrencileriydi. Fakat araştırma sonucunda ulusal program öğrencilerinin farkındalık düzeyi ortalamasının diğer gruplardan daha yüksek olduğu görülmüştür. Bu durum, araştırmanın yapıldığ1 okulun uyguladığı çevre bilinci oluşturmaya ve çevreyi korumaya yönelik uyguladığ1 aktivite, kurduğu öğrenci toplulukları, vb. çalışmaların etkili olduğu görüşünü uyandırabilir. Öte yandan, öğrencilerin çevre eğitimi kapsamında uygulamadan çok teorik olarak kitap bilgisiyle yetinmeleri, çevre koruma programı geliştirip kitlesel olarak eyleme geçirmek yerine pasif eylemlerde bulunmaları tutum ve farkındalık düzeylerinin düşük olmasina neden olacaktır.

Çevre eğitimi kapsamındaki derslerin etkililiğini artırmak için; öğrenciyi aktif hale getiren, bilgi hamallığından kurtaran ve beyin gücünü geliştiren öğretim yaklaşımlarının kullanılması gerekli hale gelmektedir. Eğitim anlayışımıza kazandırabileceğimiz farklı öğretim yöntemleri, öğrencileri ezbercilikten ve bilgi hamallı̆ından kurtararak, onların üretken, eleştiren ve kendini değerlendirebilen insanlar olmalarına katkı sağlar (Şahin vd, 2004). Programlar yenilenirken çevre eğitimi konularında laboratuvar uygulamaları, açık alan çalısmaları gibi öğrenciyi merkeze alan etkinliklerin ön planda olması ve sıklıkla kullanılması verilen çevre eğitiminin kalitesini artıracaktır.

Araştırma sonuçlarına bağlı olarak şu önerilere yer verilmiştir:

- Öğretim programlarında ve özellikle ortaöğretimde öğrencilerin çevre duyarlılığını arturacak etkinliklere daha çok yer verilmelidir

- Çevre eğitimi öğretim programlarının bir parçası olarak algılanmaktan öte bireylere yaşam felsefesi olarak kazandırılması için yaşam boyu eğitim haline getirilmelidir. Bunun için de devlet gerekli düzenlemeleri yaparak çevre eğitimini hayatın tüm basamaklarına entegre etmelidir.

- Öğrencilerin çevreyle ilgili sivil toplum örgütlerine katılımı ve aktif rol almaları desteklenmelidir.

- Okullarda öğrencilerin çevre bilinci, çevreye duyarlılı̆ı ve farkındalığını artıracak etkinlikler düzenlenmeli, onların bu etkinliklere aktif katulımları sağlanmalıdır.

- Çevre ve Şehircilik Bakanlığı, Enerji ve Tabii Kaynaklar Bakanlığı, Orman ve Su İşleri Bakanlı̆̆1 gibi devlet birimleriyle iş birliği yapılarak öğrencilerin ve bireylerin farkındalık düzeyini artıracak projeler geliştirilmelidir. 
Midilli, Ü., \& Atıcı, T. (2019). Uluslararası bakalorya diploma programı ve ulusal programda öğrenim gören öğrencilerin çevreye yönelik tutum ve çevre farkındalık düzeyleri. Journal of Human Sciences, 16(3), 846-856. doi: $10.14687 /$ ihs.v16i3.5530

\section{Kaynakça}

Aydın, H., Doğan, Y. \& Başlar, S. (2007). Ekosistem Kavram ve Öğretimi, (Editör: Yunus Doğan) Farkh Ekosistemler ve Cevre Ë̆itimi, İzmir: Çevkor.

Büyüköztürk, Ş. (2003). Sosyal Bilimler İ̧in Veri Analiæ̧i El Kitabı. Pegem A Yayıncılık. 3.Baskı Ankara. Diploma Programme Biology guide published February 2014, updated August 2015. www.ibo.org 23.09.2016 tarihinde alınmıştır.

Diploma Programme Environmental systems and societies guide published June 2015, updated August 2015. www.ibo.org 23.09.2016 tarihinde alınmıştır.

E.O. Berberoğlu \& S. Uygun. (2012). Çevre farkındalığı- çevre tutumu arasındaki ilişkinin yapısal eşitlik modeli ile sınanması. Uludağ Üniversitesi Eğitim Fakültesi Dergisi 25 (2), 459-473.

Hanna, G. (1995). Wilderness- related environmental outcomes of adventure and ecology education programming. The Journal of Environmental Education, 27 (1), 21-32.

Kulınç, A. (2010). Can project-based learning close the gap? Turkish student teachers and proenvironmental behaviours International Journal of Environmental \& Science Education 5 (4), 495 509.

Oğuz, D., Çakci, I. \& Kavas, S. (2011) Yüksek öğretimde öğrencilerin çevre bilinci, Süleyman Demirel Üniversitesi Orman Fakültesi Dergisi Seri: A, 12(1):34-39.

Özdemir, O. (2010). Doğa deneyimine dayalı çevre eğitiminin ilköğretim öğrencilerinin çevrelerine yönelik alg1 ve davranışlanına etkisi, Pamukkeale Üniversitesi Ë̈itim Fakülttesi Dergisi, 27, 125- 138.

Öztürk, M., Yilmaz, İ., Balcı, A., Norayn, Ö.F. \& Uzunoğlu, S. (1998). Çevre Eğitiminde Temel Kavramlar El Kitabı, (Redaktör: Zafer Ayvaz) İzmir: Çevre Eğitimi Merkezi Yayınları.

Palmberg, I. E. \& Kuru, J. (2000). Outdoor activities as a basis for environmental responsibility, The Journal of Environmental Education, 31 (4), 32-36.

Ann, P.J \& Moira, O. (2000). Environmental education and attitudes: emotions and beliefs are what is needed. Environment \&o Behavior, 32 (5), 711-723.

Şahin, N., Cerrah, L., Saka, A. \& Şahin, B. (2004). Yüksek Öğretimde Öğrenci Merkezli Çevre Eğitimi Dersine Yönelik Bir Uygulama, GÜ, Gari Eğitim Fakültesi Dergisi 24 (3), 113-128.

Ünal, S. \& Dımışk1 E. (1999). "Unesco-Unep Himayesinde Çevre Eğitiminin Ge-lişimi ve Türkiye’de Ortaöğretim Çevre Eğitimi”, Hacettepe Üniversitesi Eğitim Fakültesi Dergisi, 16-17: 142 - 154.

www.http://mebk12.meb.gov.tr/meb_iys_dosyalar/31/01/972850/dosyalar/2013_07/05032334_ biyoloji_912.pdf. 23.09.2016 tarihinde alınmıştır.

Xingcune, L. (2004). The role of biology in environmental education, Chinese Education and Society, 37 (4): $68-70$.

\section{Introduction}

\section{Extended English Summary}

Development of consciousness and awareness toward environment is essential to provide the sustainability of a livable environment. This is only possible with an environmental education which aims to raise individuals who have necessary characteristics. To raise individuals who are sensitive to environment and environmental problems and aware of elements that make up the environment and the functions of these elements and to nurture them with positive attitude toward environment are the key elements for preventing environmental problems and conservation of environment. It is primarily essential to educate human beings that have the most powerful effect on environment rather than legislation or manufacturing the technology to conserve the environment. Individuals that have negative attitude toward environment can be thought to be insensitive to environmental problems and even create problems. Environmental education has become an individual and social need which arises from the environmental issues that are on the global agenda. The aims of the environmental education are to raise awareness in all part of the society, to inform, 
Midilli, Ü., \& Atıcı, T. (2019). Uluslararası bakalorya diploma programı ve ulusal programda öğrenim gören öğrencilerin çevreye yönelik tutum ve çevre farkındalık düzeyleri. Journal of Human Sciences, 16(3), 846-856. doi: $10.14687 /$ ihs.v16i3.5530

to bring positive and permanent behavioral change and to provide the actively participation of the individuals. Secondary education has an important part for an environmental education which aims to provide students an environmental value system, as not all the students will achieve university education and the faculties which are not related to environment do not pay attention to environmental education. There are many studies that investigates students' the environmental awareness and attitudes toward environment in both secondary education and the related branches of universities.

As the Biology syllabus of Turkish National Education Ministry is considered, it is seen that there are some topics at the $9^{\text {th }}, 10^{\text {th }}$ and $12^{\text {th }}$ levels, which cover the titles 'recent environmental issues, natural resources and conservation of biodiversity, ecosystem ecology, biomes, communities and ecosystems' in the context of environmental education.

IBDP, is a two year preuniversity program, which is applied by International Baccalaureate Organization (IBO) located in Geneva. IBDP was developed for 16-19 year old students. It supplies the students with an international diploma in addition to the National Education Ministry diploma.

TED Ankara College Foundation High School started teaching IBDP in 1999-2000 academic year and 'Environmental Systems and Societies' lesson is included in the program in 20112012 academic year. As TED Ankara College provides both diplomas, the students studying national program and IBDP in this school were chosen as the sample of this study. Related to biology and environmental education, the students in math-science track studies the national program biology and IBDP ESS lessons while the students in Turkish-math track studies IBDP biology and national program students study biology of national syllabus.

This study aims to compare the levels of attitude toward environment and environmental awareness of students in IBDP and that of students in national program. Also it is aimed to compare the levels of attitude toward environment and environmental awareness of students who study ESS and students who do not study ESS in IBDP and according to the gender variable as well.

\section{Method}

The total study group of this investigation contains the students from high schools which apply both IBDP and national program. Considering the student numbers in schools which apply both programs, TED Ankara College Foundation High School has the highest number. Therefore, the scales were performed by 45 students from IBDP math-science track, 25 students from IBDP Turkish -math track and 39 students from national program in this school. Among 109 students participating the study were 57 females and 52 males.

'Attitude toward environment scale' and 'Environmental awareness scale', which were developed by Berberoğlu ve Uygun (2012), were performed by students to determine the levels of the students by these criteria. Appropriate statistical methods were performed to analyze the data.

Students whose end of $11^{\text {th }}$ grade average marks, for both ESS and biology lessons, are $70 / 100$ and over were included in the study to eliminate the academic succes variations of students. Average of 70 at the end of the academic year was an obligation for high level biology courses in TED Ankara College Foundation High School at the time the investigation was being conducted..

6/8 part of ESS syllabus in IBDP and all of the biology content of national curriculum which is related to environmental issues are completed by the end of $11^{\text {th }}$ grade. So, the students for the investigation were chosen from the $12^{\text {th }}$ graders.

\section{Result}

According to the analysis results, there is a statistically significant difference between the female and male students for both attitude and awareness. Average scores of girls received from both scales are higher than those of male students. Regardless of the track which the students are attending, there is not a statistically significant difference in the levels of attitude toward environment and environmental awareness between the students in IBDP and the students in national program. Also, 
Midilli, Ü., \& Atıı, T. (2019). Uluslararası bakalorya diploma programı ve ulusal programda öğrenim gören öğrencilerin çevreye yönelik tutum ve çevre farkındalık düzeyleri. Journal of Human Sciences, 16(3), 846-856. doi: 10.14687/ihs.v16i3.5530

there is not a statistically significant difference in the levels of attitude toward environment and environmental awareness between the IBDP math- science track students who receive ESS course and the IBDP turkish- math students who do not receive ESS course. Considering all the groups included in the study, there is a positive correlation between the students' levels of attitude toward environment and environmental awareness.

\section{Discussion}

It is required that the teaching approaches which activates students and improves brain power rather than loading with informatio, must be used in education in order to increase the efficiency of lessons in the context of environmental education. Different teaching methods that can be brought in the educational mentality, can protect students from memorizing and being loaded with information by helping them to be productive, critical thinkers who can evaluate themselves. When the curricula are being renewed, using activities which puts the students in the center such as laboratuary performance and open field works frequently will increase the quality of environmental education. 